\title{
Experimental study on water-salt movement of coastal saline soil
}

\author{
${ }^{\mathrm{a}}$ Y. CAI, ${ }^{\mathrm{b}} \mathrm{Z} . \mathrm{H} . \mathrm{MA}$ \\ ${ }^{a}$ Key Laboratory of Road and Traffic Engineering of the Ministry of Education, Shanghai, China \\ ${ }^{\mathrm{b}}$ Shanghai Urban Construction Design \& Research Institute, Shanghai, China
}

KEYWORD: costal saline soil, water-salt movement, column test, controlling measures

ABSTRACT: Saline soil water-salt movement results to subgrade diseases like collapsibility, salt expansion and secondary salinization in coastal areas with saline shallow water table. Column tests were carried out to study the regularity of coastal saline soil water-salt movement. Results show that coastal saline soil with a higher level of groundwater salinity has a higher capillary rising height. And both water content and salt content are higher either. Since coastal saline soil is fat clay, the increase of compaction degree may decrease capillary intense rising height, together with its water content and salt content. The findings suggest that controlling measures of coastal saline soil watersalt movement should be considered from desalination, water controlling and structural strengthening.

\section{INTRODUCTION}

Saline soil is highly sensitive to environment. Salts in soil may easily change its phase and content under the influence of water and heat, which performs as water-salt movement in soil. Saline soil water-salt movement results to subgrade diseases like collapsibility, salt expansion and secondary salinization in coastal areas with saline shallow water table influenced by climate and tide.

Water movement in unsaturated porous mediums is firstly descripted by Richards (1931) based on Darcy law. Solute movement is driven by diffusion and convection (Bresler 1972, Narasimhan 1998, Smiles et al. 1978). Models, formulated simultaneously on Richards' equation and the diffusive and convective solute transport equation, can descript capillary rise and salinization in an unsaturated soil profile (Jorenush et al. 2003, Prathapar et al. 1992). The current engineering research on water-salt movement mostly lay emphasis on agriculture production and environmental protection (Liu et al. 2007, Su et al. 2005, Yang et al. 2008), and saline soil subgrade protection in seasonal frost region (Liang et al. 2011, Liu et al. 2006).

There barely exists engineering research on water-soil movement of coastal subgrade saline soil.

Based on laboratory column test, Mou (2009) explored the distribution of water-salt in saline soil subgrade which mainly caused by fluctuation of groundwater, and then came up with some diseases controlling measures. Zhang (2012) studied water-salt movement influenced by fluctuation of groundwater and water salinity in Yellow River flood field based on laboratory subgrade model and column test. Meanwhile, the effects of groundwater depth, groundwater salinity, evaporation intensity and separation of geotextile on water-salt movement were discussed on solving Richards' equation and the diffusive and convective solute transport equation simultaneously.

With the development of coastal areas, impact of water-salt movement on engineering construction will attract more attention.

Column tests were designed to simulate the movement of saline groundwater in unsaturated saline subgrade, and to study the regularity of water-soil movement, which is mainly caused by capillary and evaporation.

\section{MATERIALS AND METHODS}

\section{Materials}

Soils for experiment were obtained from a coastal area of South Yellow Sea, which was formed through hydraulic reclamation. Some main geotechnical properties tested in laboratory are listed in 
table 1 . The result showed that the soil is medium-chlorine saline soil with high liquid limit, high plasticity index and high fine content.

On-site groundwater was obtained and then analyzed for the water-quality, which is listed in table 2.

Distilled water is also chosen for test.

Table 1. Geotechnical properties of costal saline soil

\begin{tabular}{|c|c|c|c|c|c|c|c|c|c|}
\hline & \multirow[b]{2}{*}{$\begin{array}{c}\text { Salinity } \\
(\%)\end{array}$} & \multirow[b]{2}{*}{$\frac{c\left(\mathrm{Cl}^{-}\right)}{c\left(\mathrm{SO}_{4}{ }^{2-}\right)}$} & \multirow[b]{2}{*}{$\begin{array}{l}\omega_{L} \\
(\%)\end{array}$} & \multirow[b]{2}{*}{$\begin{array}{c}I_{P} \\
(\%)\end{array}$} & \multirow[b]{2}{*}{$\begin{array}{c}\text { OMC } \\
(\%)\end{array}$} & \multirow[b]{2}{*}{$\begin{array}{c}\mathrm{MDD} \\
\left(\mathrm{g} / \mathrm{cm}^{3}\right)\end{array}$} & \multicolumn{3}{|c|}{ Particle Composition (\%) } \\
\hline & & & & & & & $<0.005 \mathrm{~mm}$ & $\begin{array}{c}0.005 \sim \\
0.074 \mathrm{~mm}\end{array}$ & $\begin{array}{c}0.075 \sim \\
0.25 \mathrm{~mm}\end{array}$ \\
\hline S1 & 1.557 & 26.4 & 55.7 & 28.1 & 17.5 & 1.755 & 22.1 & 38.1 & 39.7 \\
\hline $\mathrm{S} 2$ & 1.589 & 25.7 & 56.1 & 29.0 & 17.4 & 1.763 & 23.4 & 38.3 & 39.0 \\
\hline
\end{tabular}

Note: $w_{l}=$ liquid limit $I_{P}=$ plasticity index; $O M C=$ optimum moisture content MDD = maximum dry density.

Table 2. Groundwater quality analysis

\begin{tabular}{lcccccccc}
\hline \multirow{2}{*}{ Site } & \multicolumn{9}{c}{ Ion Content $\left(\mathrm{mg} . \mathrm{L}^{-1}\right)$} & \multicolumn{2}{c}{$\mathrm{pH}$ val- } \\
\cline { 2 - 8 } & $\mathrm{Na}^{+}+\mathrm{K}^{+}$ & $\mathrm{Ca}^{2+}$ & $\mathrm{Mg}^{2+}$ & $\mathrm{CL}^{-}$ & $\mathrm{SO}_{4}{ }^{2-}$ & $\mathrm{HCO}_{3}{ }^{-}$ & total content & ue \\
\hline 1 & 9338.2 & 347.6 & 916.0 & 16104.9 & 2011.2 & 306.2 & 32151.2 & 8.4 \\
2 & 9132.1 & 403.3 & 854.0 & 15641.4 & 2034.1 & 360.3 & 31607.6 & 8.3 \\
\hline
\end{tabular}

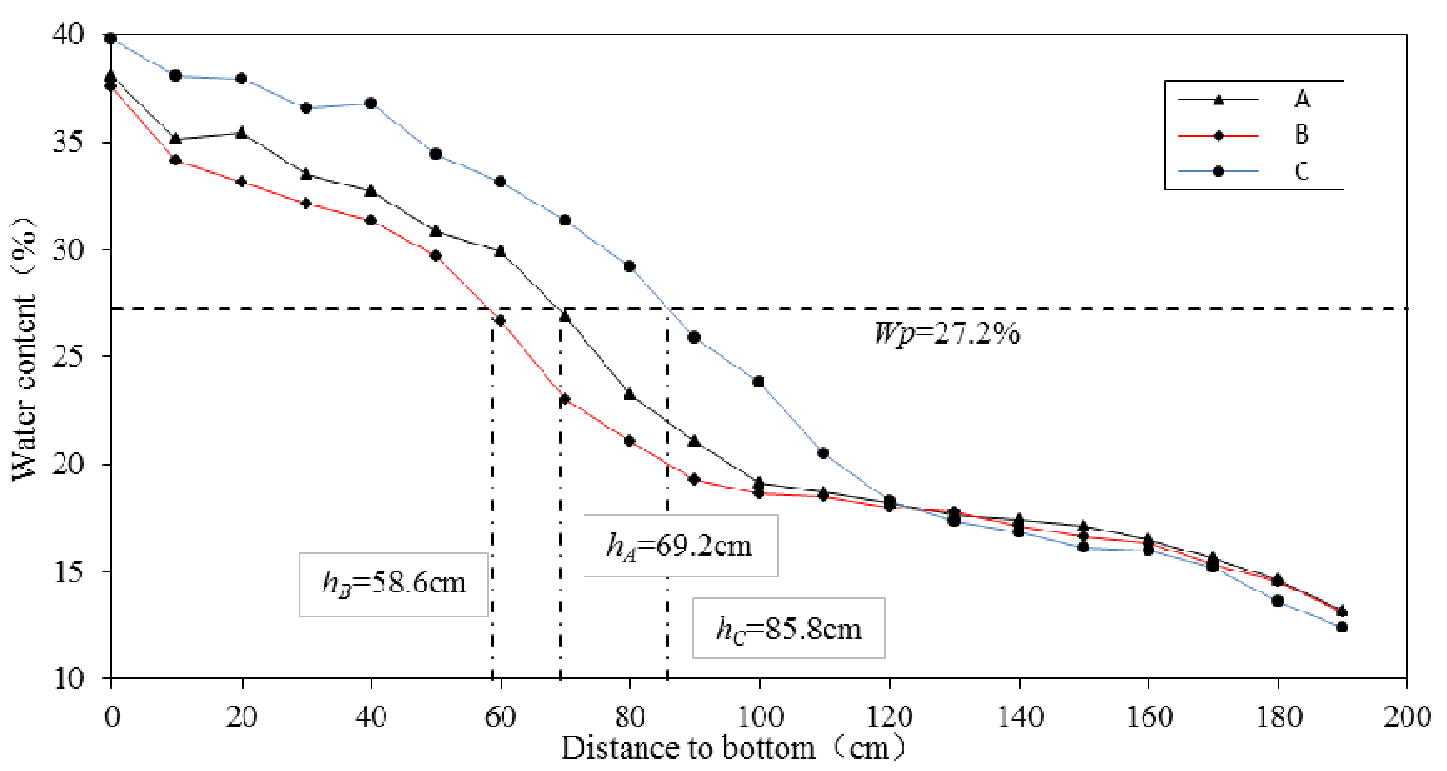

Figure 1. Water content profile after 6 months

\section{Column Test}

Operation of column test is similar to the capillary water rise test in JTG E40-2007. Soils are prepared under OMC, through installing the soil column with equal amount each time in layers. Compaction degree of soil column is controlled by exerting equal blows. After each filling, the surface of that layer should be trimmed to maintain the consistency among layers, so as to ensure the continuous of water-salt movement. The temperature of test should be kept within $20 \sim 25^{\circ} \mathrm{C}$, with sufficient water supply.

To explore the influence of groundwater salinity and compaction degree on water-salt movement, a series of column tests are designed as shown in table3. The test period is 6 months. Compaction degree of soil column can be obtained through weight and height after installing. Since the original moisture of soil column is OMC, the change of capillary water height can hardly be observed through soil color, then water and salt content are selected to be detected. 
Table 3. Scheme of column test

\begin{tabular}{llll}
\hline $\begin{array}{l}\text { Test } \\
\text { No. }\end{array}$ & $\begin{array}{l}\text { Groundwater } \\
\text { salinity }(\mathrm{g} / \mathrm{L})\end{array}$ & $\begin{array}{l}\text { Groundwater } \\
\text { depth }(\mathrm{m})\end{array}$ & $\begin{array}{l}\text { Compaction } \\
\text { degree }(\%)\end{array}$ \\
\hline A & 32.2 & 2 & 92.3 \\
B & 0 & 2 & 92.1 \\
C & 32.2 & 2 & 88.9 \\
\hline
\end{tabular}

\section{RESULTS AND DISCUSSION}

\section{Water Movement}

Water content is measured by taking the moisture test point every $10 \mathrm{~cm}$ along the column. Then, the relationship between capillary rise and water content is plotted. The capillary intense rising heights of three tests are calculated either. The results are shown in Figure 1. Conclusions obtained are shown as below:

1) With the increase of height, water content tends to decrease. Water-salt movement can be viewed as equilibrium process of soil-water potential. Water in soil column moves upwards under matric suction, and simultaneously restricted by its own weight, which leads to the water content decreases from top to bottom along the column.

2) During the 6-month test period, capillary intense rising heights of three columns turn to be $69.2 \mathrm{~cm}, 58.6 \mathrm{~cm}$, and $85.8 \mathrm{~cm}$ separately, less than the recommended value for capillary rise of clay in region IV 1, which is $1.2 \sim 1.3 \mathrm{~cm}$ (Ling 2011). It reveals that capillary water moving upwards in coastal saline soil is a slow process. This is due to the increase of water content and decrease of matric suction after some time of capillary rising. At the same time, weight of capillary water in the column increases, leading to a slower capillary rising rate.

\section{Groundwater Salinity}

Comparison between the results of A and B tests shows that, capillary intense rising height is larger in higher mineralized water, and water content is higher than soil of the same height. The main cause of this phenomenon is that the increase of groundwater salinity may enhance the surface tension of capillary water, simultaneously increasing the rising height of capillary water. When at the same height (especially within $50 \mathrm{~cm}-90 \mathrm{~cm}$ ), capillary water at highly mineralized status may provide a better supplement, making soil moisture content relatively higher.

\section{Compaction Degree}

Results from test A and $\mathrm{C}$ show that with the increase of coastal saline soil compaction degree, the value of capillary rise decreases significantly. And water content of soil with the same height decreases. It's contrary to regularity of coarse-grained soil and low liquid limit slit, which shows that capillary rise higher with the increase of compaction degree. This can be explained from the high liquid limit, high proportion of fine content, and high plasticity index of coastal saline soil. Increase of compaction degree may make its capillary-size pore smaller, and its bound water will form a thick bound water film. Abound water film in soil make part of those small pores blocked up by bound water, turning into an occlusive pore, in which water can't move. Otherwise, the unblocked pores will become smaller either and increase the tortuosity of water movement, simultaneously increasing the capillary rise resistance. Thus, capillary rising speed slows down and the water moves lower.

\section{Salt Movement}

Test points are taken every $20 \mathrm{~cm}$ along the column from the bottom, together with a test point at the top. There are 11 salt content test points for each column. Test points for salt content are actually consistent with those for water content, so soil samples for water content testing can be directly reused for salt content testing. The relation curve of capillary rise and salt content is built as Figure 2. According to the analysis of data, salt aggregates at the top of column due to strong evaporation there, making for a high salt content. 


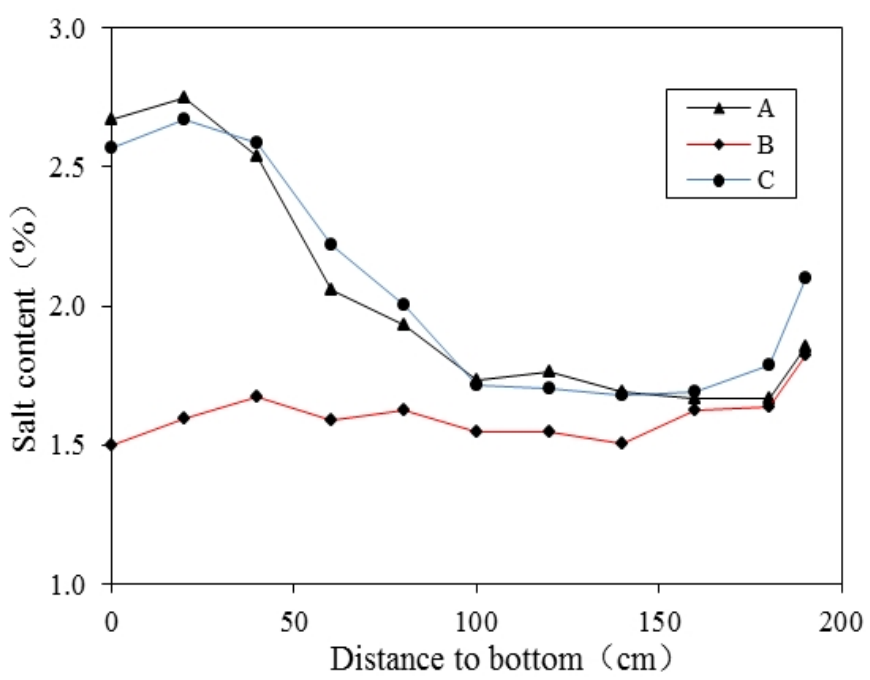

\section{Groundwater Salinity}

Figure 2. Salt content profile after 6 months

With the increase of groundwater salinity, salt content of soil in column increases. When the groundwater salinity is at $0 \mathrm{~g} / \mathrm{L}(\mathrm{B})$, there appears little difference along the vertical direction of soil in column, with salt content ranging around $1.589 \%$. When the groundwater salinity is at $32.2 \mathrm{~g} / \mathrm{L}$ (A、C), the salt content ranging within $1.665 \%$ 2.748\%. Still, from bottom to top, the salinity goes down first and then tends to stable. The corresponding height of stable point in the column is higher than the capillary intense rising height.

\section{Compaction Degree}

The vertical distributions of salt in soil columns (A、C) with different compaction degrees are similar to each other. Column with lower compaction degree has a higher water content and higher salt content.

Distributions of salt and water in column A and column C appear to have similar characteristics. Salt content decreases sharply from $40 \mathrm{~cm}$ to the top, while water content begin to decrease rapidly from $50 \sim 60 \mathrm{~cm}$ to the top. It shows that salt movement lags behind the water movement.

\section{Controlling Measures}

The column tests above show that salt supply, rapid evaporation of water, and smooth capillary channels are basic conditions for water content increasing, salt movement and gathering in subgrade. Corresponding measures to control water-salt movement in coastal saline soil should base upon three points, namely desalination, water controlling, structural strengthening.

1) Desalination measures include replacement, predissolving and chemical treatment;

2) Water controlling measures include adjusting subgrade height, setting separation layer and strengthening drainage;

3 ) Structural strengthening measures include stabilization and dynamic compaction etc.

Setting separation layer to control water-salt movement performs best in protecting saline soil subgrade from diseases. So it's one of the most common treatment measures in construction. Some common separation layers in engineering projects include geotextile, aggregate, aeolian sand and asphalt sand.

\section{CONCLUSIONS}

1) Groundwater salinity, compaction degree and evaporation condition are key elements that affect water-salt movement of coastal saline soil;

2) For a higher level of groundwater salinity, capillary intense rising height is higher. Moreover, both water content and salt content of soil columns are higher.

3) Since coastal saline soil is fat clay, the increase of compaction degree may decrease capillary rising height, together with the water content and salt content of soil columns. 
4) Measures to control water-salt movement of coastal saline soil should be considered from desalination, water controlling and structural strengthening.

\section{REFERENCES}

[1] Bresler E.,1972. Simultaneous transport of solute and water under transient unsaturated flow conditions. Water Resource Research, 9.

[2] Jorenush M.H. \& Sepaskhah A.R., 2003. Modelling capillary rise and soil salinity for shallow saline water table under irrigated and non-irrigated conditions. Agricultural Water Management , 61:125-141.

[3] JTG E40-2007, (2007). Test methods of soils for highway engineering. Beijing: China Communications Press. [in Chinese]

[4] Liang S.Q. \& Zhang F.L. \& An P.F. 2011. Research on law of water, heat and salt movement in earth frost heaving and thaw collapse. Ice Regimes in Cold Regions and Hydrological Effects of Frozen Soil : 43-46.

[5] Ling J.M., 2011. Subgrade Engineering. Beijing: China Communications Press.

[6] Liu B.C. \& Li Q.L. 2006. Numerical simulation of salt, moisture and heat transport in porous soil. Journal of Huazhong University of Science and Technology (Nature Science) 36(1) :14-16. [in Chinese]

[7] Liu C.Q. \& Yang J.S. \& Chen X.B. \& Chen D.M. 2007. Movement and redistribution of water and salt in relation to emitter discharge rate. Acta Pedologica Sinica 44(6):1016-1021. [in Chinese]

[8] Mou Y.J. 2009. Study on the transport rule of salt of inshore saline soil and how to manage the roadbed. Shandong University. [in Chinese]

[9] Narasimhan T.N., 1998. Hydraulic characterization of aquifers, reservoir rocks and soils: A history of ideals. Water Resources Research ,34(1) : 33-46.

[10]Prathapar S.A. \& Robbins C.W. \& Meyer W.S. \& Jayawardane N.S., 1992. Models for estimating capillary rise in a heavy clay soil with a saline shallow water table. Irrigation Science, 3:17.

[11] Richards L.A., 1931. Capillary condition of liquids in porous mediums. Physic, 1:318-333.

[12] Smiles D.E. \& Philip J.R., 1978. Solution transport during absorption of water by soil: laboratory studies and their practical implications. Soil Sci. Soc. Am. J., 42(4): 537-544.

[13] Su N \& Bethune M \& Mann L \& Heuperman A. 2005. Simulating water and salt movement in tile-drained fields irrigated with saline water under a serial biological concentration management scenario. Agricultural Water Management 78(3):165-80.

[14] Yang Y. \& Wang Q.J. 2008. Analysis water and salt transport characteristic of irrigation with saline water on alkaline and saline soil. Journal of Soil and Water Conservation, 22(1):13-19. [in Chinese]

[15]Zhang K., 2012. Research on the capillary water rise and salinity transport in the soil of subgrade and construction techniques in the Yellow River flood field. Shandong University. [in Chinese] 